\title{
Development and validation of a new mealtime assessment tool for patients with dysphagia
}
A. Amitrano ${ }^{1}, \mathrm{G}$
G. Rossi ${ }^{1}$, F.R. Pezzella ${ }^{2}$,
R. Latina ${ }^{3}, A . R$
F. Milito
's Camillo Forlanini Hospital, Nursing and Health Allied, Rome, Italy.
2S Camillo Forlanini Hospital, Neuroscience, Rome, Italy.
${ }^{3} S$ Camillo Forlanini, Nursing and Health Allied, Rome, Italy.
${ }^{4} \mathrm{~S}$ Camillo Forlanini Hospital, Nursing and Healt Allied, rome, Italy.
${ }^{5}$ S Camillo Forlanini Hospital, Hospital Management, Rome, Italy., Co-Authors, Institution, etc.

Background and Aims Meal observation describes and analyze patient behavoiur while taking their meal minimizing influences of the observer; it is a component of the dysphagic patient evaluation process during and after the rehabilitation phase. Tools for meal observation and in particular the MAT, for the ease of administration contemplate the possibility of involvement of the care giver, thus expanding the opportunities for use of the tool.

Aim: to develop and validate a questionnaire that could be administered by both health personel and caregivers to explore patients' mealtime behavior: the meal time assessment tool.

Method: The development and validation process was divided into three phases. The first phase included the identification of items for the questionnaire. The second phase involved pilot testing of the first version of the tool. In the final phase caregivers and the treating speech therapist administered the MAT to adult inpatients with diagnosed or undiagnosed oropharyngeal dysphagia. Correlation and internal consistency were evaluated with De Pippo and Cronbach alpha test $(>0,70)$.

Results: we enrolled 140 adult caregivers, MAT Cronbach Alpha was 0.710; we used the test of De Pippo (ROC curve) to verify the sensitivity and the specificity of the scale: results demonstated $97 \%$ sensitivity and $90 \%$ specificity. Hence it was possible to establish a patology-score cut off.

Mealtime Assessment Tool

Meal: breakfast - lunch- dinner operator:

\begin{tabular}{|c|c|c|c|c|c|}
\hline Always & Almost always & Sometimes & Almost never & Never & Not evaluable \\
\hline \multicolumn{6}{|c|}{ 2. Is the patient sitting during the meal? } \\
\hline Always & Almost always & Sometimes & Almost never & Never & Not evaluable \\
\hline \multicolumn{6}{|c|}{ 3. Are tv, tablet computer or smartphone switched off during the meal? } \\
\hline Always & Almost always & Sometimes & Almost never & Never & Not evaluable \\
\hline \multicolumn{6}{|c|}{ 4. Is the patient autonomous during the meal? } \\
\hline Always & Almost always & Sometimes & Almost never & Never & Not evaluable \\
\hline \multicolumn{6}{|c|}{ 5. Does the patient drink during the meal? } \\
\hline Always & Almost always & Sometimes & Almost never & Never & Not evaluable \\
\hline \multicolumn{6}{|c|}{ 6. Does the patient completely consume the food? } \\
\hline Always & Almost always & Sometimes & Almost never & Never & Not evaluable \\
\hline \multicolumn{6}{|c|}{ 7. Does the patient eat in silence? } \\
\hline Always & Almost always & Sometimes & Almost never & Never & Not evaluable \\
\hline \multicolumn{6}{|c|}{ 8. Does the patient eat without coughing? } \\
\hline Always & Almost always & Sometimes & Almost never & Never & Not evaluable \\
\hline \multicolumn{6}{|c|}{ 9. Is the patient's voice the same before and after the meal? } \\
\hline Always & Almost always & Sometimes & Almost never & Never & Not evaluable \\
\hline \multicolumn{6}{|c|}{ 10. After chewing, are the patient's lips cleaned of food residues? } \\
\hline Always & Almost always & Sometimes & Almost never & Never & Not evaluable \\
\hline \multicolumn{6}{|c|}{ 11. After chewing the patient's tongue is cleaned of food residues? } \\
\hline Always & Almost always & Sometimes & Almost never & Never & Not evaluable \\
\hline
\end{tabular}

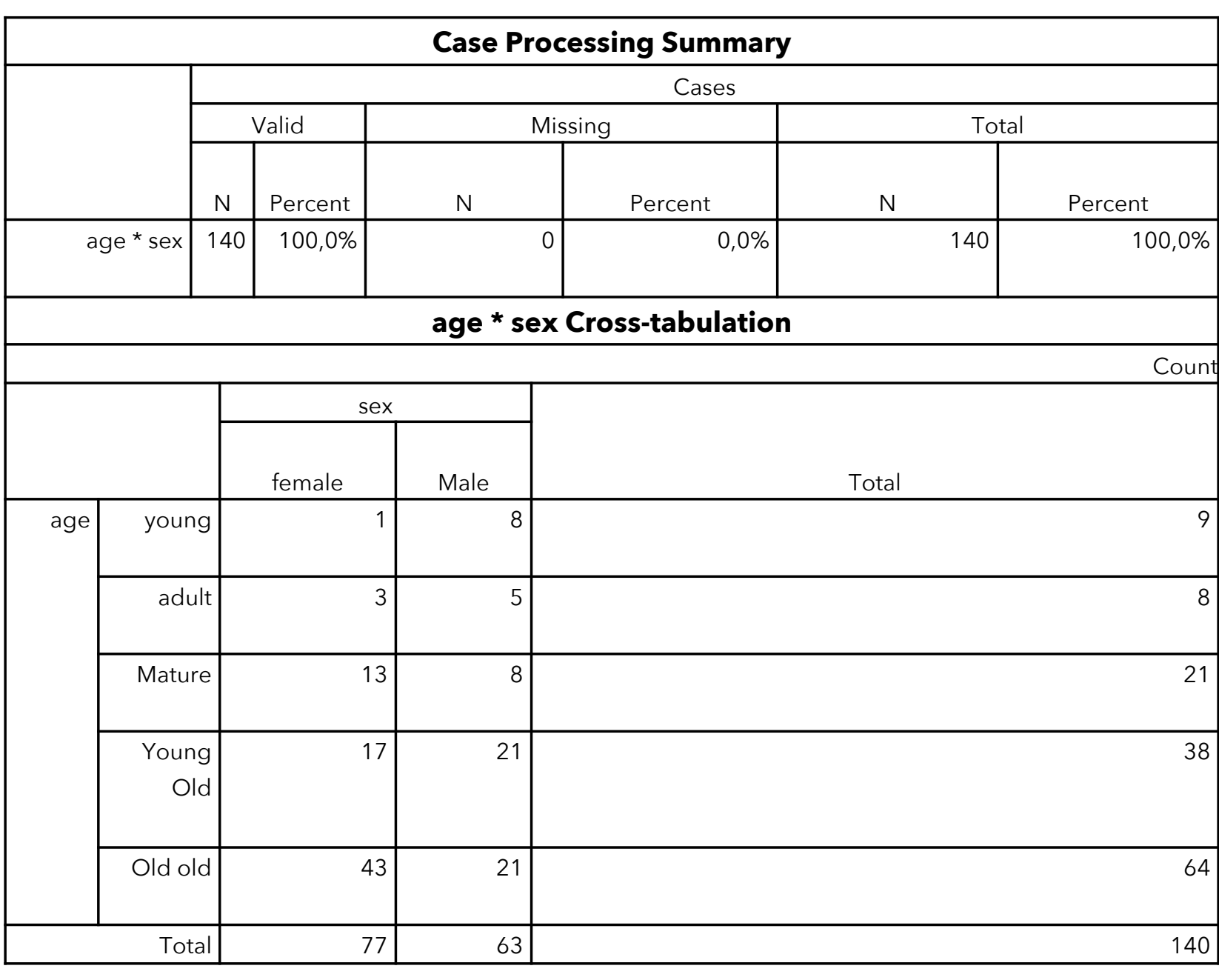

Gender-age of the sample 